\title{
Efectos emocionales que vivencian los hombres que atraviesan un proceso de divorcio
}

\author{
Emotional effects experienced by men going through a divorce process \\ Efeitos emocionais experimentados por homens em processo de divórcio
}

Jenny Jordán Casanova

jennycasan15@hotmail.com

https://orcid.org/0000-0003-0087-1503

Universidad de Aquino, Santa Cruz de la Sierra, Bolivia

Recibido: marzo 2019 / Revisado: marzo 2019 / Aceptado: abril 2019 / Publicado: mayo 2019

RESUMEN

La investigación tuvo como objetivo, determinar los efectos emocionales que vivencian los varones de 25 a 50 años los cuales atraviesa un proceso de divorcio. La metodología fue de tipo descriptiva, con un enfoque mixto y un diseño vinculado, la población estuvo conformada por 100 hombres entre los 25 a 50 años. La muestra tuvo dos etapas, 1ra etapa un muestreo aleatorio de 25 personas y para la 2da etapa, 6 hombres. La técnica e instrumentos utilizados fueron: un cuestionario, la escala de ansiedad y depresión de Goldberg (GADS), un cuestionario de estrés PSQ, y una entrevista a profundidad abierta. Se obtuvo como resultado, que es los hombres divorciados, en su mayoría han cambiado su estilo de vida. Sin embargo, los hombres a pesar de sentir efectos y cambios durante este proceso no reconocen o no admiten, verdaderamente por lo que están pasando y sintiendo.

Palabras clave: Divorcio; psicología clínica, etapas del divorcio
ABSTRACT

The objective of the research was to determine the emotional effects experienced by men between the ages of 25 and 50 who are going through a divorce process. The methodology was descriptive, with a mixed approach and a linked design; the population consisted of 100 men between the ages of 25 and 50 . The sample had two stages, 1st stage a random sample of 25 people and for the 2 nd stage, 6 men. The technique and instruments used were: a questionnaire, the Goldberg anxiety and depression scale (GADS), a PSQ stress questionnaire, and an open in-depth interview. It was obtained as a result, which is divorced men, mostly have changed their lifestyle. However, men despite feeling effects and changes during this process do not truly recognize or admit what they are going through and feeling.

Key words:

Divorce; clinical psychology, stages of divorce
RESUMO

O objetivo da pesquisa foi determinar os efeitos emocionais experimentados por homens entre 25 e 50 anos que estão em processo de divórcio. A metodologia foi descritiva, com abordagem mista e desenho vinculado, sendo a população constituída por 100 homens com idades compreendidas entre os 25 e os 50 anos. A amostra teve dois estágios, sendo $0 \quad 1^{\circ}$ estágio uma amostra aleatória de 25 pessoas e para o $2^{\circ}$ estágio 6 homens. A técnica e os instrumentos utilizados foram: um questionário, a escala de ansiedade e depressão de Goldberg (GADS), um questionário de estresse PSQ e uma entrevista aberta em profundidade. Obtevese como resultado, que os homens divorciados, em sua maioria mudaram seu estilo de vida. No entanto, os homens, apesar dos efeitos do sentimento e das mudanças durante esse processo, não reconhecem ou admitem verdadeiramente 0 que estão passando e sentindo.

Palavras-chave: Divórcio; psicologia clínica, fases do divórcio 


\section{INTRODUCCIÓN}

La relación de pareja es un nexo de amor que surge entre dos personas. Para Van Pelt (1999), esta relación tiene distintas etapas cuando evoluciona en positivo, las cuales son: La amistad, citas casuales, relación especial, relación firme, pre compromiso, compromiso formal y el matrimonio. Esta última a su vez, tiene distintas etapas las cuales van desde el enamoramiento que es la "etapa de compenetración" se complacen en lo que tiene en común y están ciegos para todo lo que los separa, hasta superación y colaboración que es donde se ven a la luz de la realidad. (Kirk, 1997). En cada etapa del matrimonio existen diversas crisis, alteraciones al igual que conflictos.

Existen tres grandes variables asociadas con los conflictos en las relaciones de pareja, que según el modelo de Bradbury son: el proceso adaptativo dentro del sistema de pareja, la resistencia del individuo a las vulnerabilidades de la pareja, y los eventos estresantes que chocan con el sistema de la pareja. Todos estos factores o variables, generan conflictos en la relación, los mismos que pueden afectar negativamente a ambos conyugues ( Parra, 2007).

Hoy en día, se ha observado que existe mayor cantidad de conflictos dentro de la pareja, como la falta de comunicación, cambiando la manera de pensar de los conyugues, la mujer se realiza como madre y a la vez como profesional trayendo esto varios cambios al hogar, como ser la falta de tiempo, celos, infidelidad generando todo esto conflictos dentro de la pareja.

Una vez instaurado el conflicto, la relación de pareja pasa a segundo plano donde lo relevante va ser, la forma en como cada uno de los miembros enfrenta y entre los dos lleguen a la solución del problema. Esto determina la manera de como asumen el conflicto en el matrimonio, considerando una importante repercusión tanto a nivel emocional como conductual. (Meza, 2010).

Además el tiempo de resolución de conflictos o acumulación de estos también puede generar malestar en la pareja.
Una de las formas de resolver o evitar el conflicto es el divorcio, considerando este proceso como una de las situaciones más estresantes en la vida de una persona. Para Yárnoz (2010), el proceso de Divorcio provoca una serie de emociones confusas y conflictivas en ambos esposos, muy similares a los de los niños que son separados de sus padres: enfado, rechazo, pena, y ansiedad o pánico son las principales.

Estos cambios no se limitan a la persona o las personas que se separan sino que involucran, a toda la familia nuclear, hermanos, amigos cercanos, y a todo su ambiente social generando efectos en cada uno de estos agentes, y a su vez incrementando conflictos en la ex pareja.

Actualmente en la mayoría de países se observa un alto índice de conflictos matrimoniales donde una de las soluciones más utilizada es el divorcio, que pasa de ser un fenómeno aislado y condenado, a ser una situación normal y muchas veces necesarias para uno o ambos conyugues.

El divorcio independientemente del sexo, es un hecho impactante emocionalmente en la vida de las personas, que desestabiliza no solo a la pareja involucrada sino a todo el ambiente que la rodea. Dependiendo de las causas, la forma de culminación del matrimonio y la manera de llevar a cabo el divorcio, las consecuencias serán variadas, llevando consigo cambios y efectos emocionales que pueden ser positivos o negativos.

Actualmente ya se habla mucho sobre las consecuencias, del divorcio tanto en los hijos como en las mujeres pero no de las consecuencias emocionales en el hombre. Debido a las características propias al género, los problemas del divorcio en los hombres no se hacen evidentes, estos quedan solapados por comportamientos aparentes, que no permiten ver los efectos reales a nivel emocional teniendo la idea errónea de que ellos no resultan significativamente afectados.

Es por ello, la investigación se basa en estudiar los efectos emocionales que deja el divorcio, pero en esta ocasión centrándose en el varón, ya que este, es un actor que no es tomado en cuenta en las 
investigaciones sobre la separación, observando que en los estudios sobre dicho problema, se interesan generalmente en las mujeres y los niños. Siendo el objeto de estudio, los efectos emocionales del divorcio en hombres de 25 a 50 años. Y la variable independiente divorcio y área emocional.

Por tal motivo, el objetivo general de la investigación es determinar los efectos emocionales que vivencian los varones de 25 a 50 años los cuales atraviesa un proceso de divorcio y asisten a servicio legal privado.

En este sentido, la presente investigación pretende responder a la falta de información que existe en la sociedad a nivel general y el concepto equívoco sobre el impacto que tiene en los hombres un proceso de divorcio.

\section{Marco teórico}

\section{Psicología clínica}

La Psicología Clínica es una especialidad de la psicología que se ocupa del comportamiento y los fenómenos psicológicos y relaciones implicados en los procesos de salud enfermedad de los seres humano. ( CNEPC, 2003).

Entre los síntomas psicológicos que atiende la psicología clínica, se encuentran los trastornos somáticos (que pueden aparecer de manera aguda o estar presentes de modo constante), los trastornos psíquicos (como la sensación de temor o las preocupaciones infundadas) y los trastornos conductuales (la inquietud motora, la irritabilidad y las perturbaciones del sueño, entre otros).

\section{Relación de pareja}

Puget y Berenstein (1989), define la relación de pareja como una conexión o correspondencia en una estructura vincular de dos personas, cuyos parámetros definitorios son:
- Cotidianeidad, que se designa como la estabilidad basada en una unidad temporal y espacial caracterizada por los intercambios diarios.

- Proyecto vital compartido, es la realización o logros ubicados en la dimensión de tiempo futuro.

- Relaciones sexuales, es la necesidad de un otro, es decir su pareja, ligada a la aceptación cómo es él o ella.

\section{Etapas de la relación de pareja (Noviazgo)}

La relación de pareja según Van Pelt, (1999), se desarrolla a través de siete etapas. Cada una tiene su función y propósito al establecer la base para la relación. Si se abrevia o elimina cualquier etapa, se produce un vacío de desarrollo en la relación y ello acarreara problemas.

Etapa 1. Amistad. Durante la amistad cada uno trata de conocer al otro mientras participa de actividades no románticas, sociales, recreativas, espirituales e intelectuales. Esta etapa es más informal y menos emotiva que las etapas finales de la relación de pareja (noviazgo), pues no existen matices románticos o sexuales.

Etapa 2. Citas casuales. Dos amigos se separan del grupo para compartir actividades que ya saben que disfrutan juntos. Como el grado de integración emocional entre ellos es bajo, ambos tienen libertad de salir con otros. No se consideran a sí mismos enamorados. Los momentos placenteros son compartidos junto con una amistad que puede prometer algo para el futuro. Una pareja debería mantenerse en la amistad y la cita incidental por seis o doce meses porque este es el tiempo que se toman para conocer sus gustos, lo que no les agrada, el origen de los hábitos y conductas. Si lo que ellos aprendieron en ese ritmo sin apuro se corresponde con lo que están buscando podrán entrar lentamente dentro de la tercera etapa. 
Etapa 3. Relación especial. Esta es una etapa donde hay un creciente afecto entre los componentes de la pareja, pero todavía no han alcanzado el grado de dedicación que requiere una relación más firme. Están dedicando más tiempo juntos, pero no están participando aun de una relación formal.

Etapa 4. Relación firme. En esta etapa hay un entendimiento entre ambos por el que no saldrán con otros. Cada uno ve al otro más a menudo que en la relación incidental o casual. Por primera vez tienen lugar las palabras dedicación y exclusivo. La relación más sostenida provee una oportunidad de observarse el uno al otro con más cuidado aunque sin compromiso de matrimonio. Esta etapa prueba también la relación con mucho más cuidado. Revela si las dos personas involucradas son capaces de mantenerse dedicadas a la misma relación, un hecho vital que debe conocerse antes de considerar el matrimonio. En esta etapa los componentes de una pareja pueden pensar que están enamorados cuando todavía pueden no tener esa certeza, porque tienen que tener en cuenta la diferencia entre amar a alguien y estar enamorado, estar enamorado es cuando la persona te atrae físicamente y estar idiotizado por lo superficial no ves el interior de la persona, en cambio amar a alguien es aceptar a la persona con sus defectos, hacer lo que bueno para esa persona.

Etapa 5. Pre compromiso. El pre compromiso es la etapa en la cual una pareja comienza a discutir la posibilidad de casarse. Hablan de casarse "algún día". Todas las conversaciones son tentativas, pero la pareja está más segura de que están hechos el uno para el otro. Su comprensión es privada y personal en lugar de ser terminal o dependiente, esto es que ya no solo implica el presente, ya están planeando a futuro y ya están viendo por terceros. Durante esta etapa una pareja puede echar una mirada en profundidad a sus estilos de vida o personalidades, para saber si son lo suficientemente compatibles como para casarse.

Etapa 6. Compromiso formal. El compromiso formal sigue al del "algún día" de la etapa previa. Este trae un profundo sentido de dedicación y pertenencia que no había en el pre compromiso. Hay unas cuantas cosas que separan el compromiso formal del pre compromiso por ejemplo: Un compromiso formal sirve como anuncio público a la familia y los amigos que una pareja tiene la intención de casarse. Ello ofrece una oportunidad de ajustarse al hecho de que se formará pronto una nueva familia, y un nuevo miembro se unirá a la familia grande.

Etapa 7. Matrimonio. El matrimonio se diferencia de las etapas anteriores en que es la última y se vincula con los procedimientos legales y los juzgados necesarios para disolver la relación por medio del divorcio. Tiene que ser la continuación de la fase romántica de cortejo, caracterizada por afectividad, respeto, cortesía y diversión. Todo junto.

\section{El matrimonio}

El matrimonio (del latín: matrimon um), es una institución social que crea un vínculo conyugal entre sus miembros. Es una unión comunitaria entre el hombre y la mujer para hacer una vida en común, llevar y soportar las cargas de la sociedad conyugal. Esta es una de las instituciones fundamentales del derecho, de la religión, del Estado, y de la vida en todos los aspectos, por tanto es la más antigua. ( Paz, 2008).

Para Peniche (2014), el matrimonio más allá de ser un vínculo conyugal, es la institución social que constituye la familia, y por ende, encontrando relación directa con las tasas de natalidad de las sociedades en donde se consoliden.

\section{El divorcio}

El divorcio (del latín divortium) es la disolución del matrimonio, mientras que, en un sentido amplio, se refiere al proceso que tiene como intención dar término a una unión conyugal. (Paz, 2008).

El divorcio es al principio una crisis vital especial porque simultáneamente engendra nuevas soluciones y nuevos problemas. Es también 
la única crisis familiar importante en la que la sociedad no presenta apoyo (Wallerstein, 1990).

Por lo tanto, el divorcio, es la ruptura de este pacto (o acuerdo) que se hace en el matrimonio, en el cual las dos partes interesadas se prometen compañía (en todas sus ramificaciones) el uno al otro. Es en efecto, una declaración de que estas promesas ya no se pueden esperar, requerir o permitir. Al eliminar estas obligaciones, un divorcio tiene por objeto dejar en libertad a los interesados para poder adquirir los mismos compromisos con otra persona. (Adams, 1989).

\section{Tipo de divorcio}

Según Paz (2008) los tipos de divorcios son:

Divorcio Notarial. La petición de este divorcio debe ser presentada de manera escrita por ambos cónyuges ante el notario o notaria, además de un acuerdo firmado entre ambos y el certificado de matrimonio correspondiente.

Divorcio mutuo acuerdo jurisdiccional. Este tipo de divorcio es el que solicitan ambos conyugues ante el Juez de lo Familiar.

Divorcio contradictorio. Este tipo de divorcio es cuando no existe un acuerdo entre ambos conyugues. Se puede pedir el divorcio introduciendo una causal muy reflexiva y objetiva que es el rompimiento del proyecto de vida en común.

Nulidad matrimonial. La nulidad matrimonial es la invalidación de un matrimonio porque en su celebración han existido o se han producido vicios o defectos esenciales que impiden que el mismo pueda surtir efectos. Por ejemplo, engaño u ocultamiento de la condición de esterilidad. La nulidad matrimonial supone que el matrimonio nunca existió, por eso es diferente al divorcio donde se reconoce que existió pero se disuelve. Los divorciados no pueden volver a casarse por el rito cristiano, por ejemplo, pero sí aquellos que consiguen la nulidad matrimonial.

\section{Etapas emocionales del divorcio}

Según Mckay (2000), las etapas emocionales del divorcio son:

El trauma de la separación. Cuando finalmente la separación tiene lugar, la primera reacción puede ser alivio, entumecimiento o pánico. El alivio suele sentirse cuando la separación ha sido un proceso largo y accidentado. Para mucha gente, el trauma de la separación física empieza tras varias semanas de entumecimiento y negación. Una reacción muy común es el súbito miedo al abandono. Aunque el miedo a la separación llega de varias maneras, la mayoría de la gente lo experimenta como aprensión o ansiedad. Se sienten física y psicológicamente vulnerables y tienen grandes problemas para concentrarse en cualquier tarea compleja. Él trauma de la separación puede durar entre unos pocos días y varios meses.

Etapa la montaña Rusa. Durante la fase de la montaña rusa se pasa de una emoción a otra a velocidad de vértigo. Si la ex pareja llama la persona se deprime. Y es ahí cuando recuerda súbitamente todas las veces que le acuso de frialdad emocional y se sienten confundido (a) por la rabia. Una de las características de esta etapa, es que la persona puede hundirse en cuestión de segundos. Basta un profundo recuerdo, una cara solitaria, o una observación de los hijos para liberar los resortes emocionales.

Etapa la construcción de la identidad. Durante esta etapa la pareja empieza a preocuparse por él o ella misma. Este nuevo narcisismo es un paso sano y necesario para recuperarse de la montaña rusa. Como la labor de la identidad empieza la persona a saborear la vida de nuevo, muchos experimentan nuevas aficiones. Durante este periodo mucha gente intenta recuperar el tiempo perdido.

Etapa el Yo recentrado. Cuando se acaba con la labor de la identidad, se puede experimentar una 
sensación de poderío y realización. Es natural que todavía sientan algo por su antiguo conyugue. Pero la mayor parte de la aflicción se supera en la etapa del recentrado. El pasado queda claramente atrás. Quizás recaigan ocasionalmente en la aflicción, pero será porque eligen seguir con sus sentimientos y no porque sean incapaz de evitarlo. La pena está allí, pero generalmente sin rencor o culpa. El presente es lo que importa ahora.

\section{Efectos del divorcio}

El divorcio produce en la pareja una gran sensación de fracaso. Aunque al principio pueda aparecer cierta sensación de liberación por haber tomado la decisión o por haber decidido solucionar un problema que ya resultaba insoportable, pronto se presenta la duda, la sensación de haber fallado, la culpa, el desasosiego y un profundo sentimiento de pérdida.

El dolor por el divorcio no es solo para la pareja, ya que ocasiona también un importante sufrimiento a los hijos. Los cambios que siguen al divorcio son muy estresantes para la mayoría de los hijos, aunque existen diversos factores que influyen notablemente en la adaptación a la nueva situación (el nivel de conflictividad entre los padres, la edad de los hijos en el momento de la separación o el divorcio, la calidad de la relación con el progenitor con el que viva, las nuevas parejas y relaciones de los padres, el sexo del hijo). ( Davison,2006).

\section{El hombre frente al divorcio}

En determinadas circunstancias, el divorcio es la mejor opción para uno o ambos miembros de la pareja. Cada caso es distinto y un mundo aparte, y no se debe generalizar. El hombre al enfrentar la ruptura matrimonial se siente frustrado y lleno de miedos que "a su manera intenta solucionar", los hombres saben esconder mejor los sentimientos, por eso parece más fácil pretender que todo se acabó y que les va bien, pero en el fondo lo que han hecho es poner una curita, encima de una enorme herida.

Un hombre que se divorcia queda generalmente solo herido: emocional, judicial y socialmente en inferioridad de condiciones. La ley lo discrimina, muchos grupos e instituciones también, el varón no es preparado para la supervivencia doméstica, y no se le reconoce a la paternidad el mismo estatus afectivo y jurídico que a la maternidad.

\section{Síntomas que experimenta el hombre divorciado}

ParaSinay (2009), los síntomas que experimenta el hombre divorciado son: Sensación de haber fracasado, miedo a que sus hijos dejen de quererlo, episodios de ansiedad y estrés por no tener a los hijos diariamente, perdida de la autoestima, inseguridad económica, miedo al cambio (estilo de vida, de hogar, de círculo social que antes compartía con su pareja), depresión, insomnio, cansancio constante, falta de concentración en el trabajo y sentimiento de culpa.

\section{MÉTODO}

La metodología que se usó para el desarrollo del estudio fue de tipo descriptiva porque se pretendió describir la situación del divorcio, y el estado emocional del varón en el proceso de divorcio. Y explicativa, ya que, se realizó una explicación de la relación existente entre el divorcio y los efectos emocionales.

A su vez, el enfoque que se utilizó para el desarrollo de la investigación, se enmarcó dentro del enfoque mixto dado que este permitió la integración sistemática del método cuantitativo y cualitativo en un estudio con el fin de obtener una "fotografía" más completa del fenómeno. A través de estudios cuantitativos se pudo obtener datos, que fueron altamente fiables, sobre los estados emocionales y los cambios con las condiciones 
comportamentales, por las que pasan los varones - mientras que la perspectiva cualitativa porque se obtuvo información sobre cómo se vivencia el divorcio desde el punto de vista personal, que el varón narró y describió a través de las entrevistas en profundidad.

A demás, el diseño de la investigación fue vinculado, el cual se caracterizó por ser un diseño de dos etapas ya que se aplicó primeramente un diseño cuantitativo que permitió aproximarse a la población y seguido de una aplicación cualitativa. Esta aplicación de dos etapas fue de manera secuencial bajo el diseño vinculado donde la primera etapa conduce a la otra. Se aplicó el diseño cuantitativo para recolectar información de los efectos emocionales y así poder identificar 'casos tipo' a extremo.

Por otro lado, la población estuvo conformada por 100 hombres que acudieron en el primer trimestre del año 2015 a servicios legales de distrito 2 por motivos de divorcio entre los 25 a 50 años. La muestra fue no probabilística seguida de un diseño vinculado, por lo tanto, la muestra tuvo dos etapas, 1ra etapa un muestreo aleatorio de 25 personas donde el requisito de los criterios de selección fueron: Casado mínimo 2 años, que tengan hijos, que atraviesen por un proceso de divorcio, aceptación para participar, nacionalidad boliviana y que tengan custodia compartida Para la 2da etapa, de los 25 sujetos se seleccionaron casos tipo o extremos según estos criterios, llegando a una muestra de 6 casos tipo. Que sientan cambios emocionales, con más de 6 meses de separación y que refieran sintomatología de malestar emocional.

Las técnicas e instrumentos que se utilizaron para la recolección de datos en la investigación fueron divididos en dos etapas.
En la primera etapa, se aplicó a 25 personas un cuestionario para recabar información sobre sus datos personales, divorcio y aspectos emocionales. El mismo, fue semi estructurada de 35 preguntas divididas en 4 ejes temáticos: Datos personales/ historia, vida matrimonial, divorcio y aspectos emocionales. La escala de ansiedad y depresión de Goldberg (GADS), su objetivo fue diagnosticar si presentó ansiedad, depresión y su intensidad. Y un cuestionario de valoración de cambios, su objetivo fue recolectar información sobre los cambios que se presentaron en los varones que pasaron por un proceso de divorcio.

En la segunda etapa se aplicó a 6 personas. Fue una entrevista a profundidad abierta con los siguientes ejes temáticos: características de encuadre biográfico, relación pasada, causa del divorcio, situación actual, efecto, cambios. Y la observación, cuyo objetivo fue describir el aspecto físico, lenguaje, contacto con entrevistadores, lenguaje no verbal, reacción emocional ante un tema, y características de la personalidad.

\section{RESULTADOS}

Para el análisis de los resultados de la investigación, se tomó en cuenta las dos etapas.

En la primera etapa, los resultados obtenidos posterior a la aplicación del instrumento 1 cuestionario, el cual fue aplicado a los 25 hombres de edades comprendidas entre 30 a 60 años, fueron:

\section{Tiempo de casados}

Se muestra en porcentaje de tiempo de matrimonio que tenían los 25 hombres entrevistados. Es decir cuántos años permanecieron casados. 
Tabla 1. Tiempo de casados.

\begin{tabular}{ccc}
\hline ALTERNATIVAS & FRECUENCIA & \% \\
\hline 2 a 6 años & 5 & 20 \\
7 a 10 años & 9 & 36 \\
11 a 20 años & 7 & 28 \\
21 a 30 años & 4 & 16 \\
Total & $\mathbf{2 5}$ & $\mathbf{1 0 0}$ \\
\hline
\end{tabular}

Los resultados confirmaron to que dice la teoría, de que las crisis con mayores consecuencias dentro del matrimonio ocurren a partir de la segunda etapa que es desde los tres años a diez años de matrimonio. Por lo tanto, en la Tabla 1, se muestra que el $20 \%$ se encuentran entre los 2 a 6 años de matrimonio, seguido de 7 a 10 años reflejándose en un $36 \%$. Por otro lado, el $16 \%$ de los encuestados se encuentran entre los 21 a 30 años de matrimonio reflejando que existe un menor número de divorcios ya que es una etapa donde la pareja se encuentra consolidada y adaptada a un ritmo y tipo de vida.

\section{Iniciativa del divorcio}

Se refleja quien tomó la iniciativa para iniciar el proceso de divorcio.

Tabla 2. Tiempo de casados.

\begin{tabular}{ccc}
\hline ALTERNATIVAS & FRECUENCIA & $\%$ \\
\hline Ella & 17 & 70 \\
Él & 8 & 30 \\
Total & $\mathbf{2 5}$ & $\mathbf{1 0 0}$ \\
\hline
\end{tabular}

La Tabla 2, muestra que un $70 \%$ de los entrevistados indicaron que la iniciativa la toma la mujer y tan solo un $30 \%$ los hombres. Quedando evidencia que la mujer es quien empieza a notar los cambios que se dan dentro del matrimonio y toma la decisión de divorciarse.

\section{Mala relación}

Se presentan los resultados del tiempo que existía una mala relación de los 25 hombres entrevistados con su ex pareja.

Tabla 3. Mala relación.

\begin{tabular}{ccc}
\hline ALTERNATIVAS & FRECUENCIA & $\%$ \\
\hline 2 a 7 meses & 18 & 72 \\
8 a 12 meses & 7 & 28 \\
Total & $\mathbf{2 5}$ & $\mathbf{1 0 0}$ \\
\hline
\end{tabular}


En la Tabla 3, se muestra que, el $72 \%$ de los entrevistados indicaron que han tenido un tiempo de mala relación con su ex pareja de 2 a 7 meses antes de iniciar el proceso de divorcio, reflejando que existe una baja tolerancia, y pocas herramientas para la resolución de los problemas, mostrando que existe una toma de decisión tan fácil para deshacer un matrimonio y desligarse rápidamente del problema pudiéndose observar que no denotan haber pasado por un tiempo prolongado de conflictos.

\section{Causas del divorcio}

Se muestran los resultados de cuáles son las causas de divorcio con mayor y menor porcentaje de los 25 hombres entrevistados.

Tabla 4. Porcentaje de causas.

\begin{tabular}{|c|c|c|}
\hline ALTERNATIVAS & FRECUENCIA & $\%$ \\
\hline Infidelidad él/ ella & 8 & 32 \\
\hline Cambios de ella & 3 & 12 \\
\hline Distanciamiento por trabajo & 2 & 8 \\
\hline Peleas físicas & 2 & 8 \\
\hline Discusiones constantes & 8 & 32 \\
\hline Vicios de juegos o consumo de alcohol & 2 & 8 \\
\hline Total & 25 & 100 \\
\hline
\end{tabular}

Las características de la sociedad actual se ven reflejadas en estos resultados ya que la causa de mayor índice de divorcios es la infidelidad de alguno de los conyugues con un $32 \%$ mostrando que ya no existe tanto respeto hacia la pareja. A su vez, esta se relaciona con los problemas de comunicación que también cuenta con el $32 \%$, que es otra de las causas con mayor porcentaje. Pudiéndose observar que la comunicación de pareja ya no existe hoy en día por el mismo hecho que ambos conyugues trabajan y tienen menos tiempo para ellos.
Por otro lado, se tiene conocimiento teórico que dos de las causas principales para tomar la decisión de divorciarse es el tema económico o la presencia de otros familiares sin embargo se pudo observar que en esta población no se reflejan estas causas.

\section{Situación emocional}

Se muestra cual es la situación emocional actual de los 25 varones en proceso de divorcio.

Tabla 5. Situación emocional del hombre posterior al divorcio

\begin{tabular}{ccc}
\hline ALTERNATIVAS & FRECUENCIA & $\%$ \\
\hline Dolor & 8 & 32 \\
Nostalgia & 8 & 32 \\
Tranquilidad & 9 & 36 \\
Total & $\mathbf{2 5}$ & $\mathbf{1 0 0}$ \\
\hline
\end{tabular}


En la Tabla 5, se muestra que un $32 \%$ de los hombres entrevistados tienen un dolor por la pérdida, seguido de otro $32 \%$ que sienten nostalgia, mostrando en total que al $64 \%$ de los hombres les ha afectado el proceso de divorcio, y que ellos ante todo sienten, yendo en contra del mito que al hombre no le afecta el divorcio y confirmando distintas teorías como la de Sinay, Slaikeu y Ellis, que refieren que el proceso de divorcio afecta emocionalmente a la persona, simplemente un $36 \%$ se encuentran tranquilos al pasar por este proceso.

\section{Situación psicológica}

Se muestran los resultados a nivel psicológico que se encuentran actualmente los varones entrevistados en proceso de divorcio.

Tabla 6. Situación psicológica.

\begin{tabular}{ccc}
\hline ALTERNATIVAS & FRECUENCIA & $\%$ \\
\hline Aislamiento & 9 & 36 \\
Insomnio & 4 & 16 \\
Preocupación & 10 & 40 \\
Felicidad & 2 & 8 \\
Total & $\mathbf{2 5}$ & $\mathbf{1 0 0}$ \\
\hline
\end{tabular}

En la Tabla 6 se muestra los malestares psicológicos en mayor incidencia como preocupación con un $40 \%$ y aislamiento con un $36 \%$ de los hombres entrevistados, lo cual es el resultado de diversos factores como, la separación con los hijos, preocupación por ellos, como también por el proceso que están viviendo el de no compartir en familia ni de convivir a diario con ellos.
Resultados del instrumento 2. Escala de ansiedad y depresión de Goldberg, el cual se muestra en porcentaje de presencia de ansiedad en los varones entrevistados donde se puede saber cuántos tienen ansiedad y cuántos no.

\section{Presencia de ansiedad}

Tabla 7. Presencia de ansiedad en el varón

\begin{tabular}{ccc}
\hline ALTERNATIVAS & FRECUENCIA & $\%$ \\
\hline No presenta & 5 & 20 \\
Leve & 3 & 12 \\
Moderado & 11 & 44 \\
Grave & 6 & 24 \\
Total & $\mathbf{2 5}$ & $\mathbf{1 0 0}$ \\
\hline
\end{tabular}


En la Tabla 7, se muestra que el $68 \%$ de los entrevistados obtuvo un nivel de ansiedad de moderada a grave, donde aparecen síntomas como taquicardia, alteraciones del sueño, dificultad de concentración que se puede deber por todas las situaciones por las que el hombre está pasando, y solo el $20 \%$ de los hombres entrevistados no presentan ansiedad.

\section{Presencia de depresión}

Se muestran los resultados donde se refleja en porcentajes cuantos de los varones presentan o no depresión.

Tabla 8. Presencia de depresión en los varones resencia de ansiedad en el varón.

\begin{tabular}{ccc}
\hline ALTERNATIVAS & FRECUENCIA & $\%$ \\
\hline No presenta & 6 & 24 \\
Leve & 5 & 20 \\
Moderado & 8 & 32 \\
Grave & 6 & 24 \\
Total & $\mathbf{2 5}$ & $\mathbf{1 0 0}$ \\
\hline
\end{tabular}

En la Tabla 8 , se muestra que el $56 \%$ de los hombres entrevistados, presentan niveles de depresión entre moderada a grave, lo cual conllevó a que dejaran de tener interés por actividades anteriormente placenteras, aumento de la fatiga, ánimo o humor depresivo.

\section{Etapa 2. Entrevista a profundidad y observación, aplicado a 6 hombres.}

\section{Entrevista en profundidad y observación: Señor 1}

El señor 1, estuvo 6 años casado, es auditor, y actualmente tiene 2 hijos con los cuales se comunica siempre, ya que viven con su madre. El señor uno, presentó en mayor medida niveles de ansiedad acompañado de un alto estrés, no presentando depresión.

En la entrevista se trabajó con el señor 1, ciertos ejes de los cuales se sintetizó lo siguientes: Relación Pasada. La relación del matrimonio en un principio fue una relación que costó mucho, ya que tenían pequeñas peleas por lo que vivían con los suegros, padres de ella. Haciendo margen de esto, la relación de matrimonio como pareja era buena ya que en su noviazgo se llevaban muy bien. El señor 1 refiere " Luego de trasladarnos e independizarnos la relación mejoro, pasaron 4 años y las peleas empezaron a hacerse más frecuentes, ya que ella reclamaba de todo o por pequeñas cosas insignificantes era realmente muy molestoso eso". Por lo tanto, ella tomo la decisión de divorciarse.

Causa Divorcio. Las peleas constantes fue el motivo principal, ya que, como se mencionó anteriormente la ex esposa reclamaba de todo lo que el señor 1 , realizaba, generando disgustos entre ellos y perdiendo la comunicación.

Situación Actual. Actualmente, él se encuentra solo sin pareja, y también vive solo, habla lo necesario sobre sus hijos con su ex esposa. Sin embargo, el Señor 1, indicó: "me di cuenta que estando juntos solo causábamos daño a nosotros mismos y a las personas de nuestro alrededor ya 
que con nuestras peleas frecuentes hacíamos que las demás personas cercanas se preocuparan por nosotros "Además, se siente preocupado por sus hijos, dado a que siente que les quito algo muy importante, como lo es la unión de la familia. Por otro lado, a nivel económico se encuentra estable y existe acuerdo en la repartición de bienes. Es importante resaltar, que el señor 1 , tiene una buena comunicación con sus hijos, lo cual esto lo reconforta ante todo los problemas, ve a sus hijos los fines de semanas porque la custodia la tiene su ex esposa y él se encarga de pagar la pensión.

Cambios. En este señor se evidenció cambios de humor, ya que refiere, "antes de la separación me sentía una persona más calmada en general, era mucho más tolerante más pasivo, hoy en día me doy cuenta que esa parte he cambiado ya que me he vuelto una persona menos tolerante". Confirmando nuevamente los síntomas de estrés y ansiedad que le está generando intolerancia, mostrando conductas agresivas e impulsivas. Otros de los cambios se ven a nivel de las actividades que realizaba ya que actualmente él trata de realizar cosas nuevas como ir al gimnasio. El señor 1 aumento el consumo de cigarrillo.

\section{Entrevista en profundidad y observación: Señor 2}

El señor 2, estuvo 7 años casado, es dueño de una licorería, y actualmente tiene un hijo con el cual se comunica, ya que vive con su madre. Presentó en mayor medida niveles de depresión acompañado de ansiedad leve y estrés muy bajo.

En la entrevista se trabajó con el señor 2, ciertos ejes de los cuales se sintetizó lo siguientes:

Relación Pasada. La relación de matrimonio en un principio refiere el señor " era una relación muy buena" ya que ambos ponían todo de su parte para que funcionara. Ellos se llevaban muy bien pero el trabajo hizo que se comenzarán alejar. Él refiere : "ella tuvo varios cambios dentro del matrimonio, se volvió una persona alzada y atrevida y la verdad no sé por qué sucedió esto, porque ella jamás se comportaba así, mm.. quizás pudo ser porque tenía un mejor trabajo". En este sentido, esos cambios hicieron que causaran muchos problemas al matrimonio, ocasionando el divorcio.

Causa de divorcio. La Falta de tiempo para estar juntos y las peleas constantes originaron el divorcio.

Situación actual. Actualmente él no tiene pareja, vive con una de sus hermanas, él no habla mucho con su ex pareja tan solo lo necesario de su hijo, están repartiendo todo en partes iguales sin ningún problema. Además, él se siente solo, bajoneado por lo que está pasando y nota muchos efectos del proceso de divorcio, el señor 2 indicó " me siento impotente por no haber solucionado el problema, siento que le estoy causando un daño a mi hijo que aunque hoy no se note todo esto va repercutir de alguna manera en él". Mostrando culpabilidad en él con respecto al crecimiento de su hijo. Por otro lado, se encuentra estable económicamente, y existe un acuerdo sobre la repartición de bienes, ve a su hijo dos veces por semana, la custodia la tiene la ex esposa y él se encarga de la pensión.

Cambios. Se pudo evidenciar cambios en el señor 2 , con respecto a cambios emocionales porque antes del divorcio, él era una persona alegre aunque con problemas pero siempre fue alegre y trabajador. Él refiere "Para evitar toda la tristeza que siento me entre a estudiar a la universidad y me estoy dedicando más al negocio que tengo". Mostrando, de esta forma, que está tomando más interés al trabajo.

\section{Entrevista en profundidad y observación: Señor 3}

El señor 3 estuvo 8 años casado, él trabaja de chofer de un camión, actualmente tiene 2 hijos con los cuales se comunica, ya que viven con su 
ex esposa. El señor 3, presenta en gran medida problemas de estrés, acompañada de ansiedad y depresión moderada.

En la entrevista se trabajó con el señor 3, ciertos ejes de los cuales se sintetizó lo siguientes:

Relación Pasada. La relación de matrimonio de él fue una relación muy buena, por la comunicación con su esposa, ya que, siempre lo entendía en todo y era una persona amable, el señor 3 refiere " luego que fueron pasando los años de matrimonio, ella se volvió una persona exigente y gritona afectando esta situación al matrimonio, en general exigiendo cosas que no estaban de acuerdo a posibilidades de nosotros" .La decisión de divorciarse fue de ella. Causa del divorcio. Los cambios en ella, hicieron que se terminará el matrimonio.

Situación actual: Él actualmente, se encuentra en una relación con otra mujer hace dos meses.

Ellos luego de tomar la decisión de divorciarse perdieron toda la comunicación, incluso para comunicarse con sus hijos lo hace por medio de la ex suegra, dado a que, con ella puede tener una buena conversación. Además, están teniendo problemas en la división de bienes, refiere el señor 3: "ella se quiere quedar casi con todo dejándome en la calle, deben ser sus celos porque me ve con mi novia". Por otro lado, se encuentra estable económicamente, y no existe acuerdo sobre la repartición de bienes, lo ve a sus hijos un día a la semana, la custodia la tiene la ex esposa y el señor pasa pensión para sus hijos. Él vive actualmente solo.

Cambios. Se pudo constatar que el señor 3, aunque no asume o no nota cambios emocionales si existen cambios en su manera de ser, él refiere "antes del divorcio era un persona fría, hoy en día eso fue cambiado, ya que, me he abierto mucho más a las personas, actualmente estoy en una relación pero sé que para llegar a un matrimonio de nuevo me va costar mucho".

\section{Entrevista en profundidad y observación: Señor 4}

El señor 4, estuvo 19 años de casado, es gerente y actualmente tiene 3 hijos, los cuales viven con su ex pareja. El señor 4, presentó en gran medida estrés acompañado de ansiedad y depresión moderada.

En la entrevista se trabajó con el señor 4, ciertos ejes de los cuales se sintetizó lo siguientes:

Relación Pasada. Su matrimonio en un principio era estable, el señor refiere,

era un matrimonio ejemplar, los últimos años mi ex esposa cambio demasiado, porque entro a la universidad a estudiar y llegaba muy tarde a mi casa, yo siempre le reclamaba eso, yo nunca llegue a una hora que no era adecuada, y no entendía lo que estaba pasando con ella, fue un cambio brusco.

En vista de aquello, él tomó la decisión de divorciarse, pues él dice que si hubo esos cambios, fueron por algo o tal vez por alguien más.

Causa del divorcio. Los cambios en ella hicieron que el matrimonio fracasara.

Situación actual. Actualmente, él se encuentra sin pareja, vive también solo, no tiene comunicación con su ex esposa, las pocas veces que han intentado comunicarse solo han discutido, y existen problemas con la repartición de bienes. Se encuentra estable económicamente, los ve a sus hijos tres veces por semana, la custodia la tiene la ex esposa y el señor 4, pasa pensiones. A pesar del divorcio, él extraña mucho a su familia, el señor refiere "me siento demasiado decepcionado y con rabia con mi ex esposa, porque ella tiene la mayor culpa, si no hubieran existidos esos cambios todo hubiera marchado muy bien".

Cambios. Se pudo evidenciar que el señor 4, está pasando por cambios emocionales donde siente nostalgia, tristeza, él refiere, 
recuerdo que antes del divorcio era una persona que le daba todo a mi familia, una persona demasiado pasiva y creo que hasta por ese mismo hecho me paso lo que me paso, hoy en día me estoy dedicando a hablar de cosas personales con mis hijos'.

Hoy en día, él nota que se está abriendo mucho más con ellos, donde trata de compartir el mayor tiempo posible. Él ha aumentado el consumo de cigarrillo.

\section{Entrevista en profundidad y observación: Señor 5}

El señor 5 estuvo 20 años casado, es ingeniero comercial, actualmente tiene 3 hijos los cuales viven con su ex pareja. Se evidenció mayor nivel de estrés con un nivel alto acompañado de ansiedad moderada, no presentando depresión.

En la entrevista se trabajó con el señor 5, ciertos ejes de los cuales se sintetizó lo siguientes:

Relación Pasada. La relación del matrimonio en un principio fue muy buena. El señor refiere "ella se volvió muy fría, celosa y gritona en lo cual esto afecto a que el matrimonio se vaya deteriorando. Luego empezaron a existir demasiadas discusiones como también peleas físicas", él menciona, que algunas veces la agredió físicamente pero que él realmente no quería hacerlo sino que es demasiado impulsivo, por esa parte, se arrepiente de haber actuado de esa manera pero sienten que la decisión de divorciarse fue la más adecuada, esta decisión fue de ella, pero él refiere "ya que la situación no iba para más".

Causa del divorcio. Las peleas físicas y reclamos hicieron que el matrimonio terminara.

Situación actual. Él actualmente tiene otra pareja hace 3 meses, vive solo dice sentirse muy a gusto con ella ya que es más joven y alegre. Refiere el señor: "me siento tranquilo la verdad, y si, algunas veces extraño, entiendo que es parte de esta etapa, proceso o como se le llame". Ve a sus hijos una vez por semana y uno de ellos no le dirige la palabra, él dice haber hecho todo para que eso se solucione con su hija pero que ella es muy orgullosa como la madre. Mencionó que se encuentra a nivel económico de una manera ajustada pero aun así pasa pensión para sus hijos, ya que, la custodia la tiene la ex esposa. El señor refiere "Ella cree que a mí me llueve la plata, no es así la cosa”. Él dice que quizás hace todo eso porque ella aun siente celos y además, porque él ya tiene otra pareja.

Cambios. Él mencionó que antes del divorcio era una persona demasiado impulsiva y un poco aburrido, pero que luego del divorcio se sintió tranquilo. Refiere "he cambiado demasiado, si me viera mi ex (risas), ,estoy dedicando a viajar a pueblos con mi pareja actual".

\section{Entrevista en profundidad y observación: Señor 6}

El señor 6 estuvo 14 años casado, él es comerciante, actualmente tiene 3 hijos los cuales viven con su ex pareja. El señor 6, presentó en mayor medida niveles depresión y estrés con un nivel alto o grave y acompañado de una ansiedad moderada.

En la entrevista se trabajó con el señor 6, ciertos ejes de los cuales se sintetizó lo siguientes: Relación Pasada. El matrimonio desde un principio fue costoso, el señor refiere "mi ex suegra siempre se metía para todo y mi ex esposa se volvió mandona, y controladora, lo cual esto, empezó a traer problemas al matrimonio". Ella tomo la decisión de divorciarse.

Causa del divorcio. Las discusiones constantes hicieron que el matrimonio se terminara.

Situación actual. Actualmente no se encuentra muy bien económicamente, tiene algunas deudas y además tiene que pasar pensión a sus tres hijos porque la ex esposa se lo exige y él entiende esa situación. Ella tiene la custodia. No se encuentra 
en pareja y vive solo, la repartición de bienes está siendo muy pasiva.

El señor refiere,

extraño mucho a toda mi familia y aunque a veces me dé un poco de vergüenza aceptarlo creo que es necesario contarlo a alguien, ya que mi familia (hermanas, padres) piensa que me encuentro bien ante esta situación porque me ven en mi tienda como si estuviera normalmente, pero el trabajo lo estoy tomando como un punto de escape, porque estando en casa me deprimo mucho más, recordando todo.

Él ve a sus hijos los fines de semana por medio y cuando está con ellos trata de aprovecharlo lo máximo.

Cambios. Antes del divorcio, él era una persona con un carácter demasiado fuerte, no niega que con su ex esposa igual era así, hoy en día, él siente que ha cambiado demasiado, sus propios amigos y familia se hacen saber. Se está dedicando más al trabajo en su tienda.

\section{CONCLUSIONES}

Después delanálisis de los resultados obtenidos, y dando cumplimiento al objetivo general de la investigación, se concluye, que los hombres a pesar de sentir efectos y cambios durante este proceso no reconocen o no admiten, verdaderamente por lo que están pasando y sintiendo.

Un proceso de divorcio en el hombre afecta la percepción de su futuro, dado a que, la mayoría tienen temor e inseguridad de iniciar nuevamente una vida matrimonial. Además, les genera mayor ansiedad y estrés, mostrando problemas en el consumo de cigarrillo, problemas de alimentación, soledad, preocupación y nostalgia.
Para finalizar, el hombre que atraviesa por un proceso de divorcio tiende a generar cambios en sus actividades sociales y laborales, las cuales no llegan a compensar los efectos negativos del mismo.

\section{REFERENCIAS}

Adams, E. (1989). Matrimonio, divorcio y nuevo matrimonio. Editorial CLIE

CNEPC. (2003). Definición que aparece dentro del programa de formación de la especialidad de psicología clínica aprobado por la CNEPC en marzo de 2003. www.uv.es/AEPCP

Davison, D. (2006). Separación y Divorcio. Editorial Intermilenio

Kirk, M. (1997). El éxito en el matrimonio. Editorial San Pablo

Meza, M. (2010). Estereotipos en el conflicto de pareja. Tesis, Barcelona, Universidad Autónoma de Barcelona, España

Papalia, D. (s/f). El libro Desarrollo Humano. Octava edición Editorial McGraw- Hill

Parra, C. Evaluación del conflicto de pareja desde la perspectiva Cognoscitiva conductual. Revista de Psicología. Vol.2

Paz, E. (2008). El matrimonio, divorcio, asistencia familiar, invalidez matrimonial, procedimientos, modelos. Cuarta edición, Editorial Servicios Gráficos "Illimani”.

Peniche, N. (2014). Matrimonio. PDF publicado el 13 de marzo del 2014

Puget, J., y Berenstein, I. (1989). Psicoanálisis de la pareja matrimonial. Volumen 128 de Biblioteca de psicología profunda. Editor Paidós

Van Pelt, N. (1999) Etapas del noviazgo. Revista Dialogo

Yárnoz, Y. (2010). Sagrario bienestar psicológico en progenitores divorciados: Estilo de apego, soledad percibida y preocupación por la ex pareja. Revista Clínica y Salud, Vol.21. Madrid, España 